\title{
EXTRA SKELETAL EWINGS SARCOMA OF SMALL INTESTINE ORIGIN: A CASE REPORT
}

\author{
K. S. Satyavani1 ${ }^{1}$ Sriharsha Haranadh ${ }^{2}$
}

\section{HOW TO CITE THIS ARTICLE:}

K. S. Satyavani, Sriharsha Haranadh. "Extra skeletal Ewings Sarcoma of Small Intestine Origin: A Case Report". Journal of Evolution of Medical and Dental Sciences 2015; Vol. 4, Issue 02, January 05; Page: 278-281,

DOI: $10.14260 /$ jemds/2015/43

ABSTRACT: This is a case report of Ewing's sarcoma/PNET arising from small intestine, a rare presentation of Ewing's sarcoma. The case presented as a mass per abdomen with no other associated symptoms and after excision of the mass along with the adjacent mesentery, the histopathology and immunohistochemistry reported as Ewing's/PNET with clear margins. Follow up of the case showed no recurrence. This case is reported for its rare occurrence, as only few cases are reported in literature.

KEYWORDS: Extra skeletal ewings sarcoma, a rare case report.

INTRODUCTION: Ewing Sarcoma was described by James Ewing[1] in 1921 as an undifferentiated tumor involving the diaphysis of long bones that, in contrast to osteosarcoma, was radiationsensitive. Although most often a primary bone tumor, ES was also reported to arise in soft tissue (Extraosseous Ewing sarcoma [EES]) ${ }^{[2]}$

Ewing sarcoma (ES) and peripheral primitive neuroectodermal tumor (PNET) were originally described as distinct clinicopathologic entities.[3] However, over the last several decades, it has become clear that these entities comprise the same spectrum of neoplastic diseases known as the Ewing sarcoma family of tumors. Ewing's sarcomas represent $16 \%$ of primary bone sarcomas.[4]

Extraosseous Ewing's sarcoma is a rare tumor. Histopathological appearance is similar to those found in Ewing's of bone origin. The annual incidence of extra-osseous Ewing's was 0.2 per million of population between 1970 and 2004. The five-year survival rate for extra-osseous Ewing's was $62 \%$, which is significantly better than previously reported in the literature. Indicators of a poor prognosis were extra-compartment spread of tumour, local recurrence and metastasis.

CASE REPORT: A 25year old female patient presented with mass per abdomen, to surgery OPD at Government General Hospital, Kakinada, East Godavari District in May 2012, which she noted 5 months back. She noticed that the mass was moving along with the change of posture. Mild pain around the umbilical region and decrease in appetite are the only associated features. General examination of the patient was normal.

On local examination, an intra-abdominal mobile firm mass of about $10 \times 6 \mathrm{~cm}$ with irregular surface is present at umbilical and left lumbar region

Laboratory blood investigations (Hb-10.2\%, RBS-106mg/dl, BUN-20mg/dl, serum creatinine$0.9 \mathrm{mg} / \mathrm{dl}$ HIV-negative, HbsAg-negative, HCV-negative, BGT-A+ve) and X-rays of abdomen are normal.

Abdominal ultrasound reported as heterogenous lesion, ill-defined noted in the umbilical region-? GIST. 


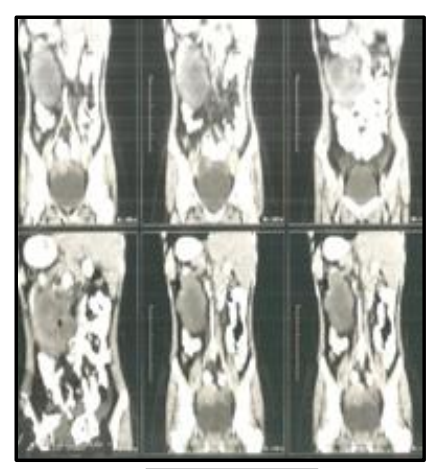

Fig. 1

Fig. 1: Abdominal CT scan reported as large heterogeneously enhancing hypodense mass lesion involving left lumbar region appears exophytic from distal jejunal loops s/o Leiomyosarcoma/GIST.

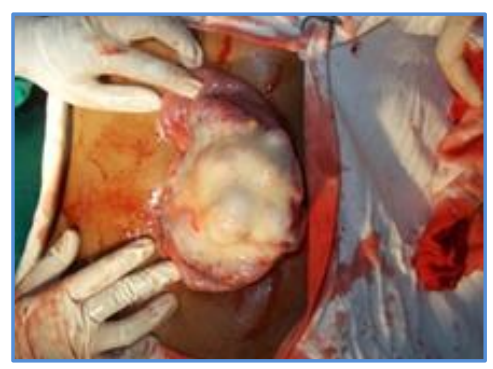

Fig. 2

Fig. 2: Intraoperative findings are -a growth of size 15 x 8cm (horizontal to vertical) involving $15 \mathrm{~cm}$ of jejunum and the adjoining mesentery, about $20 \mathrm{~cm}$ distal to the Duodeno-jejunal flexure was identified. Resection (with $5 \mathrm{~cm}$ margin of bowels) followed by end to end anastomosis was done. Postoperative course of the patient was satisfactory and was discharged on $12^{\text {th }}$ postoperative day.
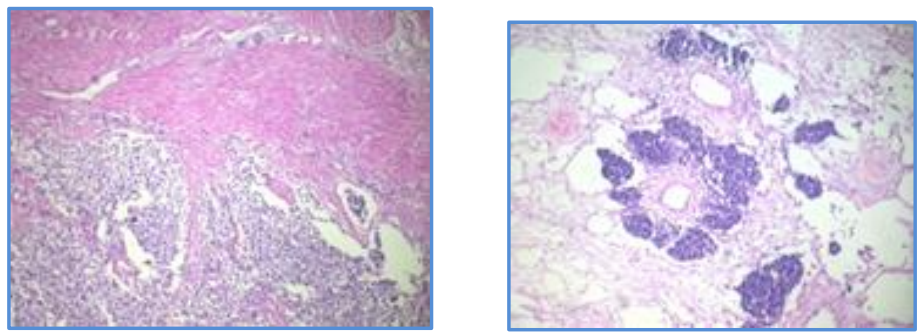

\section{Fig. 3}

Fig. 3: Pathological findings are - grey brown nodular mass at the antemesenteric border. Cut sections showed mass extending into the lumen of the intestine.

Sections studies from the mass showed sheets of small round cells with scant cytoplasm and round to oval vesicular nuclei. Pseudo-rosette formation is seen at some places. Resected margins free from tumor. Sections from lymphnodes show features of sinus histiocytosis. Immunohisto chemistsy studies showed positive for CD 99 and S 100.

POST OPERATIVE CHEMOTHERAPY- VAC alternating with IE regime is given every 21 days. 9 cycles of VAC and 8 cycles of IE (Total of 17 cycles) are given for a period of 52weeks. 


\section{CASE REPORT}

V-VINCRISTINE $2 \mathrm{mg}$ IV on day 1

I-IFOSFAMIDE $1800 \mathrm{mg} / \mathrm{mt} 2$ on days $1-5$

A-ADRIAMYCIN $75 \mathrm{mg} / \mathrm{mt} 2$ IV on day

1 E-ETOPOSIDE $100 \mathrm{mg} / \mathrm{mt} 2$ on days $1-5$

C-CYCLOPHOSPHAMIDE $1200 \mathrm{mg} / \mathrm{mt} 2$ IV on day1

DISCUSSION: The Ewing sarcoma family of tumors includes Ewing sarcoma, peripheral primitive neuroectodermal tumor, neuroepithelioma, atypical Ewing sarcoma, and Askin tumor (Tumor of the chest wall). The tumors in the Ewing sarcoma family are treated similarly on the basis of their clinical presentation (eg, metastatic or localized) rather than their histologic subtype. Translocation $\mathrm{t}$ (11; $22)^{[5-6]}$ or one of a series of related translocations occurs in more than $95 \%$ of the Ewing sarcoma family of tumors.

Extraosseous Ewing tumor/pPNET is a very rare lesion demonstrating aggressive behaviour and frequent recurrence. According to case reports, the sites most often affected are the soft tissues of the extremities, chest (Askin's tumor) and retroperitoneum. Additional sites reported are kidney, bladder, external genitalia and more rarely, digestive tract, ${ }^{[7-8]}$ parapharyngeal space, skin, orbit and abdominal wall.

The typical case of ESS is characterized by a solid pattern of small, round, lobulated cells. The individual cell has a round or oval nucleus of 10-15 $\mu \mathrm{m}$ in diameter with fine chromatin and one or two nucleoli. In many cases the cytoplasm is vacuolated as a result of intracellular deposition of glycogen that may compress the nucleus. The clinical picture depends on tumor location and size, mainly manifested by pain and inflammation at the affected area. When the lesion involves peripheral nerves or spinal roots, sensory and motor disturbances occur.

Histological documentation is necessary, and specific staining studies are performed. Electron microscopy and immunohistochemistry as says are used to accurately define this tumor with the presence of structural glycogen in the cell cytoplasm, reaction to transcriptases or the expression of specific proteins in the tumor cell membrane.

The generally suggested treatment for Extra skeletal Ewing's sarcoma lesion is based on the same principles as the treatment suggested for Ewing bone tumor. Early diagnosis is followed by extensive surgery combined with chemotherapy and high-dose radiotherapy for a favourable outcome and low incidence of recurrence. These same principles are implemented in the treatment of extra medullary tumors.

There are reports of neo adjuvant treatment, i.e., initial chemotherapy followed by removal of the lesion and then followed by new cycles of chemo- and radiotherapy. In the literature there are only case presentations. ${ }^{[9]}$ Literature review of EES shows it to be an extremely rare lesion and, for that reason, it is not feasible to carry out comparative studies to determine the most effective multidisciplinary management. Therefore, we do not know if with this type of localized tumor it is feasible to begin with chemotherapy and then follow with surgery and/or radiotherapy, as done in Ewing bone tumors.[10]

Treatment for an unsuspected Ewing's tumor that presents with a mass abdomen and radiological features suggest a Stromal tumor, is extensive tumor resection after intraoperative study of a biopsy of the lesion. If necessary, en bloc removal with adjacent involved organs should be performed to prevent recurrence. Final histopathological results must be awaited for treatment planning to determine the need for chemo and radiotherapy. 
CONCLUSION: Extraosseouss Ewing's Sarcoma is a rare tumor. When it occurs in the abdominal cavity, it may show signs and symptoms related to intra-abdominal organs due to their displacement and compression. Diagnosis requires specific immunohistochemical studies. Reported cases and studies to compare the best line of management are very few. Comprehensive treatment should include chemo- and radiotherapy along with surgery.

\section{REFERENCES:}

1. Ewing, J. (1921). "Diffuse endothelioma of bone". Proceedings of the New York Pathological Society 21: 17-24.

2. Angervall L, Enzinger FM. Extraskeletal neoplasm resembling Ewing's sarcoma. Cancer 1975; 36:240.

3. Askin FB, Rosai J, Sibley RK, et al. Malignant small cell tumor of the thoracopulmonary region in childhood: a distinctive clinicopathologic entity of uncertain histogenesis. Cancer 1979; 43:2438.

4. Goldman (24th ed. ed.). Philadelphia: Elsevier Saunders. p. 1326. ISBN 978-1-4377-2788-3

5. Collini p Sampietro G, Bertulli R, Casali PG, Luksch R, Mezzelani A, et al. cytokeratin immunoreactivity in 41 cases of ES/PNET confirmed bimolecular diagnostic studies. Am J Surg Pathol 2001; 25: 273-274.

6. D Alava E, Gerald WL, Molecular biology of ES/PNET family J Clinoncol 2000;18:204-213.

7. Adair A, Harris SA, Coppen MJ, Hurley PR, Extraskeletal Ewings sarcoma of small bowel; case report and literature review J R Coll Surg Edinb 2001;46:372-374.

8. Colovic RB, Gruber NM, MIcev MT, Matic SV, Atkinson HD, Latincic SM, Perigastric Extraskeletal Ewings sarcoma. A case report. World J Gastroenterol 2009; 15: 245-247.

9. Tracker MM, Temple HT, Scully SP, Current treatment for Ewing's sarcoma. Expert Rev Anticancer Therapy 2005; 5: 319-331.

10. Venkitaraman R, George MK, Raman SG, Sagar TG. A singular institution experience of combined modality management of Extraskeletal Ewing's sarcoma. World J SurgOncol 2007; 11: 5-13.

\section{AUTHORS:}

1. K. S. Satyavani

2. Sriharsha Haranadh

\section{PARTICULARS OF CONTRIBUTORS:}

1. Assistant Professor, Department of General Surgery, Rangaraya Medical College, Kakinada.

2. Senior Resident, Department of General Surgery, Rangaraya Medical College, Kakinada.

\section{NAME ADDRESS EMAIL ID OF THE} CORRESPONDING AUTHOR:

Dr. K. S. Satyavani,

D/No. 45-7-22,

Gudimetla Vari Street,

Jagannaikpur, Kakinada-533002,

East Godavari District,

Andhra Pradesh.

E-mail: drvaniss@gmail.com

Date of Submission: 24/12/2014.

Date of Peer Review: 26/12/2014.

Date of Acceptance: 29/12/2014.

Date of Publishing: 05/01/2015. 